\title{
A língua do/no Brasil: efeitos da memória e da história
}

Caroline Schneiders ${ }^{a}$

\begin{abstract}
Resumo
No presente estudo, procuramos desenvolver uma reflexão que tem por objetivo compreender a memória constitutiva do discurso sobre a língua do/no Brasil no início do século XX, a partir das obras: A defesa da língua nacional (1920), de Laudelino Freire, e A língua do Brasil (1947), de Gladstone Chaves de Melo. Por meio dessas materialidades discursivas, interessa-nos observar a maneira como a história e a memória afetam e determinam o modo como a lingua do/no Brasil é significada em diferentes conjunturas sócio-histórica e ideológica. O referencial teórico em que nos ancoramos vincula-se à perspectiva da História das Ideias Linguísticas, articulada aos pressupostos teórico-metodológicos da Análise de Discurso de linha pecheuxtiana.
\end{abstract}

Palavras-chave: Língua. Memória. História. 


\section{Considerações iniciais}

Neste estudo realizamos uma reflexão que versa sobre a compreensão da memória constitutiva do discurso sobre a língua do/no Brasil no início do século $X X^{1}$. Tendo em vista esse interesse, selecionamos, como objeto de análise, dois importantes discursos que discutem a questão da língua, situados na primeira metade do referido século, a saber: $A$ defesa da língua nacional (1920), de Laudelino Freire, e A língua do Brasil (1947), de Gladstone Chaves de Melo. Por meio dessas materialidades discursivas, observamos a maneira como a história e a memória afetam e determinam o modo como a língua do/no Brasil é significada em determinada conjuntura sócio-histórica e ideológica.

O referencial teórico que embasa essa reflexão ancorase na perspectiva da História das Ideias Linguísticas (HIL), articulada aos pressupostos teórico-metodológicos da Análise de Discurso (AD) de linha pecheuxtiana. Nessa perspectiva em que nos situamos, não trabalhamos com uma metodologia pronta e fechada, justamente pelo fato de a HIL, articulada à $\mathrm{AD}$, propor um olhar interpretativo sobre o objeto de análise. Assim, a partir do dispositivo teórico oferecido pela AD, mobilizamos, conforme a nossa questão de interesse sobre o objeto de análise, nosso dispositivo analítico, o qual, no entanto, vai se constituir ao longo do percurso de análise, em um constante ir e vir da teoria para a análise e/ou vice-versa, como o movimento de um pêndulo (PETRI, 2013).

Além disso, cabe destacar que, para analisar as materialidades mobilizadas, realizamos recortes discursivos, buscando destacar aqueles que nos possibilitam explicitar o nosso interesse. É por meio dos recortes discursivos delimitados que construímos nossos gestos de interpretação, os quais permitiram compreender os efeitos de sentido que ressoam

${ }^{1}$ Uma primeira versão deste estudo foi apresentada junto ao XI Congresso Internacional da Associação LatinoAmericana dos Estudos do Discurso - ALED. dos discursos sobre a língua no/do Brasil em determinadas condições de produção, efeitos esses que entendemos estarem vinculados às políticas linguísticas ligadas tanto ao 'efeito ideológico da colonização' (MARIANI, 2004) quanto ao efeito da 'descolonização linguística' (ORLANDI, 2009). 


\section{O discurso sobre a língua: algumas considerações}

Para o desenvolvimento desse estudo, consideramos que todo conhecimento é uma realidade histórica, constituído por um horizonte de retrospecção e de projeção, os quais indicam que $\mathrm{o}$ ato de saber relaciona-se a um passado, por meio de um conjunto de conhecimentos antecedentes e, ao mesmo tempo, a um futuro que dele se desdobra. Entendemos, pois, que "sem memória e sem projeto, simplesmente não há saber" (AUROUX, 1992, p. 11). Ou seja, o conhecimento está em relação ao tempo e não há conhecimento instantâneo, por ele estar situado em dado momento na história e afetado por uma exterioridade que o constitui.

Dessa forma, ao considerarmos a determinação constitutiva da prática discursiva, estaremos atentando ao modo como a história inscreve-se na língua e produz efeitos de sentido. A história, a partir da perspectiva em que nos situamos, não se define como uma simples cronologia de acontecimentos, como a evolução dos fatos, refere-se à filiação de sentidos, ao modo como os fatos são analisados e interpretados (ORLANDI, 1996). A história, segundo Orlandi (1990, p. 35), "está ligada a práticas e não ao tempo em si. Ela se organiza tendo como parâmetro as relações de poder e de sentidos, e não a cronologia: não é o tempo cronológico que organiza a história, mas a relação com o poder (a política)".

A história não é considerada como algo exterior ao discurso, é parte de sua constituição, configurando uma temporalidade que é interna a ele e possibilitando a historicização de determinados saberes/dizeres (AUROUX, 2008; PUECH, 2006). Para Auroux (2006), fazendo referência ao domínio da história das ciências, não se pode verificar uma temporalidade extrínseca, mas sim uma temporalidade que é interna a tal domínio, constituindo-o e produzindo efeitos de sentido. A temporalidade torna-se, portanto, uma característica interna e essencial às ciências, instaurando o funcionamento dos horizontes de projeção e de retrospeç̧ão.

No entender do autor (1992, p. 11), "todo conhecimento é uma realidade histórica", vinculado a um horizonte de retrospecção e de projeção, sendo o horizonte de retrospecção fundamental para compreendermos a historicidade e a memória que afeta e configura a prática discursiva. Tal 
horizonte estrutura-se de diferentes modos, apontando para o fato de que o conhecimento está em relação ao tempo e que não existe conhecimento instantâneo (idem, 2008).

Tendo em vista a determinação histórica dos discursos e o fato de nos interessarem de modo especial os discursos sobre a língua do/no Brasil, torna-se relevante destacar o que entendemos como discurso de e discurso sobre. O discurso sobre é, nas palavras de Orlandi (1990, p. 37), "uma das formas cruciais da institucionalização dos sentidos", sendo um "lugar importante para organizar as diferentes vozes (dos discursos de)". Não podemos pensar no discurso de sem levar em consideração o discurso sobre; são categorias indissociáveis, imbricadas na formulação discursiva para produzir efeitos de sentido.

Porém, é preciso considerar que cada categoria está investida de um funcionamento em particular: pelo discurso $d e$ "é possível identificar e analisar o sujeito enunciador que se identifica de alguma forma com o sujeito universal, toma uma posição e, consequentemente, produz seu discurso" (PETRI, 2004, p. 319); já pelo discurso sobre, podemos observar funcionamentos que conduzem a efeitos de sentido contraditórios, pois, na medida em que se procura recuperar uma memória, organizando os discursos de, "corre o risco de reduzir esta memória a um acúmulo de informações sobre o passado" (ibid., p. 29).

Venturini (2009) ressalta que o discurso de permite ao sujeito filiar-se à dada Formação Discursiva (FD), retomando o já dito em seu discurso, isto é, é o que "sustenta o dizer, autorizando-o ou não em relação à FD" (p. 75). Já o discurso sobre, para a autora, constitui-se pelo discurso de, sustentandose nessa memória histórica e permitindo que se tenha a institucionalização do dizer e dos sentidos, uma vez que "traz para o intradiscurso outros enunciados, que atuam como seus fundadores" (p. 79). A autora ainda ressalta que o retorno de determinados dizeres pode estar associado à "citação ou pelo funcionamento do interdiscurso, enquanto pré-construído, como efeito do discurso-transverso" (p. 75).

A partir dessas considerações, é possível entender que o discurso de e o discurso sobre estão vinculados ao funcionamento do discurso fundador. Um discurso torna-se fundador na medida em que "cria uma nova tradição, ele 
ressignifica o que veio antes e institui aí uma memória outra. É um momento de significação importante diferenciado" (ORLANDI, 1993, p. 130). O discurso fundador instaura-se, sobretudo, por sua relação com o já dito, pois é sustentando-se no já dito que se tem a possibilidade de movimentar os sentidos.

O discurso fundador, ao criar outra tradição, instaura outros sentidos ou, mais precisamente, outras filiações de sentidos, configurando um novo lugar de memória, ou seja,

Cria tradição de sentidos projetando-se para a frente e para trás, trazendo o novo para o efeito do permanente. Instalase irrevogavelmente. É talvez esse efeito que o identifica como fundador: a eficácia em produzir o efeito do novo que se arraiga no entanto na memória permanente (sem limite). Produz desse modo o efeito do familiar, do evidente, do que só pode ser assim" (ORLANDI, 1993, p. 13-14).

Interessa-nos destacar a noção de discurso fundador, uma vez que, para nós, quando instaurado, podemos considerá-lo como um discurso de, permitindo que outros discursos se constituam, tendo como ancoragem tal filiação de sentidos e lugar de memória. Com isso, podemos compreender a historicidade dos processos discursivos e o modo como estão constituídos em relação a outro(s) discurso(s), possibilitando a configuração de discursos sobre, que, por sua vez, tomam como referência um discurso de. A historicidade tem, portanto, um papel fundamental, e é pela historicidade dos processos discursivos que observamos o modo de instauração de um discurso fundador, bem como de novos sentidos.

Além disso, o discurso fundador configura-se por uma relação de conflito com o processo de produção dominante de sentidos, conflito este que produz a ruptura, o movimento dos sentidos, que estabelece outra filiação de memória e um novo sítio de significância (ORLANDI, 1993). Podemos, ainda, enfatizar a importância das condições de produção para a configuração de um discurso fundador, as quais são determinantes para a produção do discurso e dos sentidos.

Considerando nosso objetivo de analisar discursos sobre a língua, observar essa relação existente com o discurso de e com o discurso fundador é fundamental, uma vez que as materialidades em análise nos permitirão compreender a filiação de sentidos e de memória constitutivas desses discursos em torno da língua do/no Brasil. 


\section{A memória e a história da e na língua}

Para compreender a memória e a história inscritas no fio do discurso, trazemos, primeiramente, para a discussão, alguns recortes discursivos da conferência proferida por Laudelino Freire, em 1920, intitulada: A defesa da língua nacional. A mobilização desse discurso sobre a língua do/no Brasil deve-se à posição que é discursivizada na horizontalidade do discurso. Para refletirmos sobre essa posição, partimos do título de sua conferência: "A defesa da língua nacional". Pelo título, já podemos adiantar que seu discurso versa sobre a defesa de uma língua considerada nacional. Por língua nacional entendemos, conforme Guimarães, que "é a língua de um povo, enquanto língua que o caracteriza, que dá a seus falantes uma relação de pertencimento a este povo" (GUIMARÃES, 2007, p. 64).

Interessante também destacar que tal conferência foi promovida pel'A liga da defesa nacional, ou seja, à época, anos de 1920, tornava-se necessário uma aliança/união que defendesse os 'direitos' nacionais, ou da nação. Através dessa conferência de Laudelino Freire, compreendemos, portanto, a importância da língua para refletir sobre questões como nacionalidade e nação.

Ao considerarmos a conjuntura dos anos de 1920, sabemos que se trata de um período em que a discussão sobre a constituição da nação brasileira adquire força em todas as esferas, ganhando inúmeros adeptos e tornando-se um símbolo ideológico seja no âmbito político, seja no econômico ou cultural, afetando/determinando, igualmente, os estudos sobre a língua. A respeito da questão da língua, considerando o processo de colonização linguística do Brasil, Orlandi afirma que

\footnotetext{
o que está em questão, não é somente a predominância de uma língua sobre as outras, nem mesmo a questão da língua do Estado, mas a língua enquanto signo de nacionalidade, ou seja, em sua relação com a nação. E é nesse sentido que será percebida a diferença da língua no Brasil em relação à língua em Portugal (ORLANDI, 2001, p. 24).
}

Com relação ao discurso de Laudelino Freire, ele nos aponta justamente para essa importância de pensar o Brasil, à época, como uma nação, como o próprio autor destaca: “[...] Antes de tudo precisamos de ser uma nação, e não um simulacro, uma apparencia, um arremedo de nação. [...]" 
(FREIRE, 1920, p. 15). Para tanto, Laudelino destaca que é imprescindível a língua para poder se constituir como uma nação, entendendo que:

RECORTE 1:

“Entre os elementos orgânicos de uma nação, é o idioma a revelação mais eloquente do espirito de nacionalidade do mesmo passo, o vínculo mais forte da união nacional." (FREIRE, 1920, p. 16).

Diante disso, considera que é necessário 'conservar a língua', com vistas à 'homogeneidade idiomática', apontando, contudo, para a dificuldade dessa conservação, questionandose sobre os seguintes aspectos:

RECORTE 2:

"Mas, como articular, em condições de exequibilidade, a defesa de uma lingua, que tudo trabalha para vasá-la «nos residuos impuros de um idioma de alluvião», ao revés de "espelhá-la nessa lingua decantada e transparente, que a tradição filtrou no curso dos tempos"? Como se deve traduzir o nosso empenho pela tornar mais nacional, mais estimada, mais pura e mais vernacula?" (FREIRE, 1920, p. 16).

A fim de reivindicar a defesa do idioma nacional, Laudelino Freire fundamenta seu ponto de vista partindo do que chamamos de 'descolonização linguística', argumentando a favor do fato de que 'nos libertamos econômica e politicamente', o que propulsou a emancipação da literatura e, consequentemente, a consolidação de nossa cultura, como nos aponta o seguinte recorte:

RECORTE 3:

"A lingua portuguesa, sabei-lo, é patrimonio commum de dois povos. Portugueses no-la herdaram, e portugueses foram os que no-la ensinaram. Ao cabo, porém, de um viver quatro vezes secular, no transcurso do qual, com superioridade innegavel, nos libertámos economica e politicamente, logrando em seguida a emancipação da literatura, não fôra de esperar, hoje, que a nossa cultura, zelo, orgulho, nos não désse a certeza de que já somos um povo, que possue, como os demais, a sua lingua, e, como os demais, sabe exigir que todos lh'a reconheçam como propria.

E essa condição é, senhores, o primeiro passo na defesa do idioma, porque com ella é que madrugamos na jornada larga que temos que fazer, é ella que nos imporá o sermos tão zelosos delle quanto o são delle ciosos outros que tambem o fallam. Sim. Se ha quasi um seculo lográmos desempeçar 
as asas das mãos que as detinham, razão hoje não ha para que consideremos, a nós mesmos, empecilhados no em que nos cumpre ser absolutamente autônomos. Cada povo com a sua lingua." (FREIRE, 1920, p. 17).

Por meio do recorte acima, podemos compreender que há um discurso sobre a língua que rompe com os sentidos de unidade linguística, trazendo à baila um discurso em defesa das especificidades da língua que se fala no Brasil. Ou seja, esse discurso vincula-se ao efeito produzido pelo processo de descolonização linguística, o qual, a partir de Orlandi, vem a funcionar nesse espaço de ruptura da língua portuguesa de Portugal e da língua portuguesa do Brasil. A descolonização linguística envolve, portanto,

[...] esse imaginário no qual se dá também um acontecimento linguístico desta vez sustentado no fato de que a língua faz sentido em relação a sujeitos não mais submetidos a um poder que impõe uma língua sobre sujeitos de uma outra sociedade, de um outro Estado, de uma outra Nação (ORLANDI, 2009, p. 172).

Nesse sentido, podemos dizer que o discurso de Laudelino Freire posiciona-se em defesa de que o Brasil possui sua língua, uma língua que foi herdada de Portugal, mas que, hoje, possui características distintas, permitindo considerála com uma língua outra. Trata-se, pois, de considerar que a língua do/no Brasil situa-se na tensão entre o mesmo e o diferente' (PFEIFFER, 2001; ORLANDI, 2002).

Argumentando a favor de uma língua nacional, Laudelino Freire enfatiza o posicionamento errôneo daqueles que consideram a língua brasileira como um dialeto, bem como a ideia de produzir um dicionário de brasileirismos, que seria, segundo ele, um "desserviço trazido à língua". A negação da existência de brasileirismo, como bem propõe Pfeiffer (2001), justifica-se porque se faz necessário o retorno a Portugal, a origem das formas linguísticas criticadas. Para Laudelino Freire,

RECORTE 4:

“Não basta á lingua ter o seu diccionario. Lingua que não tem a sua physionomia, a sua individualidade, o seu genio, não é lingua. Será linguagem de Bengala ou de Angolla, Loanda ou Ajudá. O genio da lingua está na sua syntaxe, como na construção está a sua individualidade." (Laudelino Freire, 1920, p. 24). 
Também é contrário à ideia da reforma ortográfica proposta à época:

\section{RECORTE 5:}

"Não. A orthographia de uma lingua não é coisa que se reforme. Ortographia estuda-se, esclarece-se, mediante a etymologia; simplifica-se mediante a acção secular; e uniformiza-se consoante os esclarecimentos e investigações de casos controvertidos. Nunca jámais se lhe poderá alterar radicalmente, e por decreto, a feição tradicional, legitima e legitimada, senão admittir e consagrar as alterações que lhe vão sendo determinadas pela acção do uso e do tempo. Através dessas transformações ha de, porém, ater-se aos laços de origem, vinculada indissoluvelmente aos elementos genitores, que a produziram." (FREIRE, 1920, p. 30).

Por fim, propõe alguns aspectos que devem ser levados em prol da língua nacional, a saber:

\section{RECORTE 6:}

"Eis, senhores, o que se me afigurou conveniente dizer-vos em prol da lingua nacional, cuja defesa, em synthese, deve antes de tudo e acima de tudo, versar nos seguintes pontos:

a) fortalecer a convicção de que, como os demais povos cultos, possuimos uma lingua, e não um simples dialecto, pejado de corruptelas e de palavras prenhes de mysterios;

b) organizar o dicionário da lingua e deixar de parte a idéa de um dicionário de brasileirismos, por prejudicial ás prerrogativas do idioma;

c) diffundir de norte a sul do paiz o ensino do vernaculo, sem desamparar nunca a autoridade tradicional, para o que o primeiro passo será levar ao conhecimento de todos - intellectuaes, mestres, professores e estudantes - esse livro de luz e oiro, que é Replica, como synthese daquela orientação, como a melhor das grammaticas e o repositório mais completo das opulencias, da graça, da belleza e indole nativa do bom falar, do bom dizer e do bom escrever;

d) tornar accessivel a leitura dos bons autores e melhores classicos, nomeadamente Ruy, Camões, Sousa, Bernardes, Vieira, Felinto, Elyso, Castilho, Herculano, Camillo, Francisco Lisbôa, Machado de Assis, Gonçalves dias, Latino, Garret, alem de outros; para que a linguagem vernacula se vase nos moldes da syntaxe e construção consoante ao gênio da lingua, porque isso é o que lhe imprime individualidade e caracteristica, e não vá sendo ella traducção intraduzivel de idiomas alheios; 
e) propugnar a pureza do vocabulario, defendendo-o contra a invasão de toda sorte de peregrinismos, mui principalmente dos galicismos, que lhe tiram o sabor nativo; e, por ultimo,

f) uniformizar a grafia nacional, estribada na origem e transformação dos vocabulos e consagração do uso, sem lhes tirar ou alterar fonemas indispensaveis á sua inteligência, á sua significação e á sua esthetica." (FREIRE,1920, p. 37-38).

Ao finalizar a conferência, Laudelino Freire reitera a questão de que é necessário trabalhar "pela restauração da língua, pela sua pureza e pela conservação das suas prerrogativas e do seu genio" (FREIRE, 1920, p. 39).

Vemos, pois, um nacionalismo materializado pelo modo como se concebe a língua do Brasil, uma língua que é herdada de Portugal, mas que já é nacional e que caracteriza o território brasileiro. Ou seja, no discurso de Laudelino Freire, observamos que as designações Língua Portuguesa, Língua nacional e Língua brasileira são tomadas como sinônimas. No entender de Dias (2001), o que "estava em jogo [era] um conceito de cidadania; isto é, a questão da nacionalidade da língua estava em função de uma imagem discursiva do falante, enquanto membro de uma nação" (DIAS, 2001, p. 192).

Verificamos "um apagamento de Portugal, trabalhandose uma identidade própria para a língua nacional brasileira que já não mais precisa da referência à língua de Portugal para garantir sua unidade" (PFEIFFER, 2001, p. 180). Assim, observar os estudos sobre a língua torna-se importante, visto que, como ressalta Guimarães, ao "estabelecer a diferença do português do Brasil relativamente ao português de Portugal [tiveram] papel decisivo na constituição da nacionalidade brasileira" (GUIMARÃES, 2003, p. 47).

Considerando a outra materialidade por nós mobilizada, a saber: A lingua do Brasil (1947), de Gladstone Chaves de Melo, o autor destaca, no capítulo VII, intitulado "Língua e Estilo", a problemática em torno da questão da 'língua brasileira', considerando que, à época, para refletir sobre essa questão, deixava-se de lado a distinção fundamental entre o que é língua e o que é estilo. 
Para o autor, essa distinção está pautada na dicotomia langue e parole, estabelecida por Ferdinand de Saussure. Refletindo sobre a questão do estilo na língua, Gladstone destaca o seguinte:

\section{RECORTE 1:}

“[...] do mesmo modo que há um estilo individual, haverá um estilo nacional. Quer dizer: se existe um espírito nacional, um temperamento, um caráter, uma sensibilidade, um modode-ser nacional, também, por isso mesmo, existirá uma expressão lingüística que reflita êsse modo-de-ser, essa, por assim dizer, alma coletiva. Paralelamente à língua nacional, há um estilo nacional [...]." (MELO, 1947, p. 133).

A partir do recorte acima, podemos observar que o autor entende, pois, que a mesma língua pode ser constituída por mais de um estilo nacional, a exemplo da língua portuguesa. Partindo desse pressuposto, Gladstone considera equivocadas as conclusões que surgem a favor de uma língua brasileira. Segundo seu ponto de vista, no caso da língua do Brasil, devemos partir do conceito de 'estilo nacional', o que nos permite ter uma língua portuguesa e um estilo brasileiro.

Diante disso, propõe que o "português usa a língua portuguesa à feição do temperamento luso, com estilo português, e o brasileiro usa a língua portuguesa conforme ao temperamento nosso, com estilo brasileiro" (1947, p. 134). Para ele, é, portanto, "esse estilo brasileiro, que vem palpitando ora mais vivo, mais nítido, ora mais tímido, mais escondido, na pena dos nossos grandes escritores, a partir do Romantismo", provocando interpretações que levam a propor a existência de uma língua brasileira.

Ao destacar que "Língua é sistema, estilo é expressão", o interesse de Gladstone é:

RECORTE 2:

"[...] insistir na diferença entre as duas coisas, procurando caracterizar uma e outra, buscando delimitar-lhes o campo, para que se evitem as lamentáveis confusões reinantes no espírito de boa parte dos defensores da "língua brasileira". (MELO, 1947, p. 144).

Podemos relacionar essa discussão de Gladstone à discussão que teve início na década de 1930 a respeito da 
denominação da língua do Brasil. No entanto, foi somente no ano de 1946 que a língua do Brasil foi nomeada como sendo a língua portuguesa, pela Assembleia Constituinte. Sobre isso, podemos retomar os estudos de Dias (1996; 2001) que tratam dessa problemática, envolvendo as designações língua portuguesa e língua brasileira.

Tendo em vista esses discursos sobre a língua por nós mobilizados, podemos dizer que, em ambos, ressoa a memória da colonização, cuja memória resulta do fato de o discurso estar sujeito à determinação dos fatos externos, das condições históricas, que irrompem na discursividade enquanto 'processos de ressonâncias de significação' (SERRANI, 1997). Isto é, decorrem do funcionamento do interdiscurso, pelo que é anterior e exterior ao dito (pré-construído) e pelo retorno do saber ao pensamento (efeito de sustentação), permitindo a inscrição, na formulação do discurso, de uma determinada memória discursiva.

Podemos dizer que tanto no discurso sobre a língua de Laudelino Freire, como no de Gladstone Chaves de Melo, está marcada a relação entre a língua portuguesa de Portugal e a língua portuguesa do Brasil. Contudo, apontam também para o caráter diferenciado que essa língua adquire no Brasil. Para o primeiro, a língua é o elemento fundamental para a constituição da nação. Diante disso, entende que a língua nacional do Brasil não é a mesma língua de Portugal, visto que é pela língua que a Nação ganha singularidade, caracterizando o seu povo e criando em seus falantes um imaginário de pertencimento a ela (GUIMARÃES, 2003).

Já para o segundo, a língua portuguesa é a mesma tanto no Brasil como em Portugal, diferenciando apenas o estilo. O que se coloca no discurso de Gladstone não é a questão de língua enquanto símbolo da Nação, mas uma questão teórica, partindo, portanto, de uma concepção fundamentada de língua e fala, retomando os pressupostos saussurianos para propor seu ponto de vista. É interessante compreender os dois discursos, pois, enquanto num vemos a relação com a nacionalidade, noutro vemos um discurso pautado teoricamente para dizer sobre a língua. 


\section{Considerações finais}

A memória que ressoa nesses discursos aponta, portanto, para o fato de que o

'outro' perpassa toda a discussão sobre a identidade linguística do Brasil. Ora ele se apresenta como a contraparte constitutiva do mesmo, ora ele se instala no próprio espaço de identidade interna da língua (DIAS, 2001, p. 197).

Nesse sentido, conforme enfatiza Orlandi,

o 'mesmo' abriga, no entanto um 'outro', um 'diferente' histórico que o constitui ainda na aparência do 'mesmo': o português-brasileiro e o português de Portugal se recobrem como se fossem a mesma língua, no entanto não são (Orlandi, 2002, p. 23)

e isso passa a ser significado de maneiras diferentes, conforme as posições que os sujeitos assumem diante dessa problemática e conforme a conjuntura sócio-histórica e ideológica em que se inscrevem.

A partir de nosso ponto de vista, entendemos que essas discussões que perpassam os discursos sobre a língua, sobretudo, nas primeiras décadas do século XXI, são decorrentes de políticas linguísticas que afetam a historicização da língua portuguesa no Brasil, a qual coloca em evidência a relação da língua com a exterioridade. Essa relação, no entanto, não é vista da mesma forma pelos estudiosos da época, cujas interpretações versam sobre a unidade e a diversidade da língua; ou ainda, nos termos que estamos considerando, os posicionamentos dos estudiosos sobre a língua diferenciam-se conforme o entendimento que os mesmos possuem acerca da relação entre 'o mesmo' e o 'outro'/'diferente' constitutivo da língua do/no Brasil.

Para nós, retomando as palavras de Orlandi, o português do Brasil

é uma historicização singular, efeito da instauração de um espaço-tempo particular diferente do de Portugal [...]. Espaço-tempo este estruturado pelos sujeitos e pelos objetos que o ocupam e com capacidade linguística particular (Orlandi, 2009, p. 48).

Nesse sentido, pensar a língua portuguesa é pensar que ela se liga a duas histórias e a duas estruturas distintas; não se trata de uma língua homogênea, ela é heterogênea não só em 
relação a Portugal e ao Brasil, mas também quanto à língua que circula, a que se liga a cada Nação.

Ao observamos as ressonâncias de significação dos discursos sobre, que se vinculam tanto ao 'efeito ideológico da colonização' quanto ao efeito da 'descolonização linguística' (ORLANDI, 2009), compreendemos a maneira como a história se inscreve na língua, produzindo efeitos de sentido, e, principalmente, a historicidade constitutiva dos discursos sobre a língua. Logo, tanto o processo de colonização quanto o de descolonização linguística se constituem sob dadas condições sócio-históricas, produzindo relações singulares com uma memória que é própria ao país colonizado e ao país colonizador.

\section{REFERÊNCIAS}

AUROUX, S. A revolução tecnológica da gramatização. Trad. Eni P. Orlandi. Campinas, São Paulo: Editora da Unicamp, 1992. Les modes d'historicisation. In: CHEVILLARD, J.-L. (org.) Histoire Épistémologie Langage. Paris: SHESL, 2006. p. 105-116. A questão da origem das línguas, seguido de A historicidade das ciências. Trad. Mariângela Pecciolli Gali Joanilho. Campinas, SP: Editora RG, 2008.

DIAS, L. F. Os Sentidos do Idioma Nacional: as bases enunciativas do nacionalismo linguístico no Brasil. Campinas, São Paulo: Editora Pontes, 1996.

O nome da língua do Brasil: uma questão polêmica. In: Orlandi, E. (Org.) História das Idéias Lingüuisticas: construção do saber metalingüístico e constituição da língua nacional. Campinas: Pontes, 2001, p. 185-197.

FREIRE, L. A defesa da língua nacional. Rio de Janeiro, 1920.

GUIMARÃES, E. Política de línguas na linguística brasileira. In: Orlandi, E.; Guimarães, E. (Orgs.). Política Lingüística no Brasil. Campinas, SP: Pontes, 2007, p. 63-82.

. Enunciação e Política de Línguas no Brasil. Revista

Letras - Espaços de Circulação da Linguagem, vol. 1, n. 27, p. 47-53, jul.-dez. 2003.

MARIANI, B. Colonização linguística: línguas, política e religião no Brasil (séculos XVI a XVIII) e nos Estados Unidos da América (século XVIII). Campinas: Editora Pontes, 2004. 
MELO, G. C. de. A língua do Brasil. 2. ed. Fundação Getúlio Vargas, 1971 [1946].

ORLANDI, E.; GUIMARÃES, E. Formação de um espaço de produção linguística: a gramática no Brasil. In: ORLANDI, E. (Org.). História das Idéias Lingüísticas: construção do saber metalingüístico e constituição da língua nacional. Campinas: Editora Pontes, 2001, p. 21-38.

ORLANDI, E. Terra à vista: discurso do confronto: velho e novo mundo. Campinas: Editora da Unicamp, 1990.

. Discurso fundador: a formação do país e a construção da identidade nacional. São Paulo, Campinas: Editora Pontes, 1993. . Exterioridade e Ideologia. Cadernos de Estudos Lingüísticos. Campinas, no 30, p. 27-33, jan.-jun., 1996.

. Lingua e conhecimento linguístico: para uma história das idéias no Brasil. São Paulo: Cortez, 2002.

Lingua Brasileira e Outras Histórias: Discurso sobre a língua e ensino no Brasil. Campinas: Editora RG, 2009.

PFEIFFER, C. A língua nacional no espaço das polêmicas do século XIX/XX. In: Orlandi, E. (Org.) História das Idéias Lingüisticas: construção do saber metalingüístico e constituição da língua nacional. Campinas: Editora Pontes, 2001, p. 167-183. PETRI, V. O Funcionamento do Movimento Pendular Próprio às Análises Discursivas na Construção do "Dispositivo Experimental" da Análise do Discurso. In: PETRI, Verli; DIAS, Cristiane (Org.). Análise de Discurso em Perspectiva - Teoria, método e análise. Santa Maria: Editora da UFSM, 2013, p. 39-48.

Imaginário sobre o gaúcho no discurso literário: da representação do mito em Contos Gauchescos, de João Simões Lopes Neto, à desmitificação em Porteira Fechada, de Ciro Martins. 2004. 332 f. Tese (Doutorado em Letras) - Universidade Federal do Rio Grande do Sul, Porto Alegre, 2004.

PUECH, C. Pour une historie de la linguistique dans l'histoire de la linguistique. In: CHEVILLARD, J.-L. (org.) Histoire Épistémologie Langage. Paris: SHESL, 2006. p. 09-24.

SERRANI, S. M. A linguagem na pesquisa sociocultural: um estudo da repetição na discursividade. Campinas. SP: Editora da Unicamp, 1997.

VENTURINI, M. C. Imaginário urbano: espaço de rememoração/ comemoração. Passo Fundo: ED. UPF, 2009. 


\section{Abstract \\ The language of / in Brazil: effects of memory and history}

In this study, we develop a reflection that aims to understand the constituent memory of discourse about language of / in Brazil in the early twentieth century, from the following works: A defesa da língua nacional (1920), by Laudelino Freire, and A língua do Brasil (1947), by Gladstone Chaves de Melo. Through these discursive materialities, we are interested in observing how the history and memory affect and determine how the language of / in Brazil is signified in different socio-historical and ideological circumstances. The theoretical support which this work is based on is linked to the perspective of the History of Linguistic Ideas, articulated to the theoretical and methodological assumptions of Discourse Analysis from Pecheux.

Keywords: Language. Memory. History. 